\title{
LA HISTORIA DE LA ECONOMÍA Desde Platón hasta los Romanos*
}

\author{
THE HISTORY OF THE ECONOMY \\ From Plato to the Romans \\ A HISTÓRIA DA ECONOMIA \\ De Platão aos Romanos
}

Revista LOGOS CIENCIA \& TECNOLOGÍA ISSN 2145-549X,

Vol 4. No. 1, Julio - Diciembre, 2012, pp. 82-95

\section{Resumen}

A lo largo de este artículo se analizará el nacimiento de la ciencia económica. Si bien la economía se constituyó como ciencia a mediados del siglo XVIII, la ansiedad por los procesos económicos en las sociedades se remonta a las civilizaciones de Grecia y Roma. Lo "económico" juega un rol central en la organización de las distintas sociedades históricas, ya que se encuentra ligado a su subsistencia -provisión de alimentos-, organización del trabajo, intercambio de recursos. El origen del pensamiento económico moderno tiene su inicio en la antigua Grecia.
Fecha de Recepción: 27 de enero de 2012

Fecha de Aceptación: 11 de abril de 2012

* Este artículo es producto del Grupo de Investigación "Liderazgo" de la Universidad Militar Nueva Granada, Registro ante Colciencias COL0015722 Clasificado en A1.

* Economista de la Universidad Militar Nueva Granada, Máster en MIBE, MIB de la Escuela Española de Negocios Internacionales EENI (España). Actual Jefe de la División de Investigación Científica de la Universidad Militar Nueva Granada., Email: henry.acuna@unimilitar.edu. co, hacuna2007@gmail.com
Los filósofos griegos fueron los primeros en analizar y reflexionar acerca de distintas cuestiones relacionadas con lo que hoy se conoce como economía. Las temáticas tratadas por los pensadores griegos, en líneas generales, están relacionadas con la actividad comercial que tuvo un incipiente desarrollo durante los siglos IV y III a. C. Aunque pensadores griegos como Heródoto' ${ }^{1}$, Teuclides², Hesiodo ${ }^{3}$, y Jenofonte ${ }^{4}$ se dedicaron al estudio de la economía, aportando algunas teorías, pero es a partir de Platón

Heródoto de Halicarnaso. Fue un historiador y geógrafo griego que vivió entre el 484 y el 425 a. C.

2 Teuclides. Matemático griego. Poco se conoce a ciencia cierta de la biografía de Euclides, pese a ser el matemático más famoso de la Antigüedad.

3 Hesíodo. Nació en Ascra, cerca de Tebas hacia la segunda mitad del siglo VIII a. C. o la primera del siglo VII a. C. Fue campesino e hijo de un comerciante.

4 Jenofonte. Nació en las cercanías de Atenas, en la región de Ática, durante la segunda mitad del siglo V a. C., en el seno de una familia acomodada. Su infancia y juventud transcurrieron durante la Guerra del Peloponeso (431404 a. C.), en la que participó formando parte de las fuerzas ecuestres. Fue discípulo de Sócrates. Escribió su obra 
y Aristóteles que se puede encontrar conceptualizaciones más sistematizadas en relación con aspectos económicos de la vida en "la polis".

Para los propósitos del presente estudio se hizo uso de fuentes documentales; es una propuesta exploratoria histórica, que describe los inicios de la economía que hoy se conoce, mediante documentos, libros, recopilaciones que han analizado ilustres intelectuales, compilados a lo largo de la historia.

También, tiene como objetivo demostrar la importancia histórica de las culturas griega y romana para con la economía y la importancia para la humanidad; aunque según el estado del arte, no se evidencia mucha información de estas culturas y el aporte a la economía.

Palabras claves: Doctrinas economías, Economía, Filósofos, Grecia, Roma, Platón.

\section{Abstract}

Throughout this article we analyze the birth of economic science. While the economy was established as a science in the mid-eighteenth century, anxiety about economic processes in society dates back to the civilizations of Greece and Rome. The "eco-

Oikonomicos, que viene a ser la primera contribución al estudio de la ciencia económica.

5 El establecimiento de Polis o ciudades-estado fue la innovación política más importante de los antiguos Griegos.

Durante la era micénica, los griegos habían vivido en pequeños reinos guerreros. Sin embargo, por razones desconocidas, alrededor del año 1200 a. de C., la gente abandonó sus ciudades.

A partir de ese momento, los griegos vivieron agrupados en tribus, tanto sedentarias como nómadas. Este período es conocido como la Edad Oscura Griega, y finalizó alrededor del año 800 a. de C.

La Edad Oscura Griega fue quedando atrás cuando las tribus crecieron y pasaron a conformar unidades políticas más grandes. El comercio entre los pueblos creció notablemente y florecieron los mercados. Los pequeños poblados empezaron a unirse entre sí formando unidades defensivas más grandes y construyendo fortificaciones en común.

La Polis fue un elemento clave en un período de experimentación política que tuvo gran influencia en las formas de gobierno que se adoptaron posteriormente alrededor del mundo. nomic" plays a central role in organizing the various historical societies, and that is linked to their subsistence food supply, work organization, resource sharing.

The origin of modern economic thought has its beginning in ancient Greece. The Greek philosophers were the first to analyze and reflect on various issues related to what is now known as economics. The topics addressed by the Greek thinkers in general, are related to commercial activity had barely begun during the IV and III centuries a. C.

Although Greek thinkers such as Herodotus, Teuclides, Hesiod and Xenophon were devoted to the study of the economy, contributing to create some theories; it is from Plato and Aristotle that can be found more systematic conceptualizations regarding economic aspects of life in "the polis".

This study made use of documentary sources, is a historical exploration proposal, describing the beginnings of the economy is now known, from documents, books, collections that have analyzed illustrious intellectuals who have managed to compile over history.

Also aims to demonstrate the historical importance of Greek and Roman cultures to the economy and the importance to mankind, even as the state of the art, not much information is evidence of these cultures, and the contribution to the economy.

Keywords: Doctrines economies, Economy, Philosophers, Greece, Rome, Plato

\section{Resumo}

Ao longo deste trabalho o nascimento da ciência econômica. Enquanto a economia como uma ciência foi criada em meados do século XVIII, ansiedade sobre processos econômicos nas sociedades remontam às civilizações da Grécia e de Roma. O "econômico" desempenha um papel central na organização de várias sociedades históricas, como ela está ligada a sua oferta de alimentos de subsistência, organização do trabalho, a partilha de recursos. A origem do pensamento econômico moderno tem o seu início na Grécia antiga. Os filósofos gregos 
foram os primeiros a analisar e refletir sobre várias questões relacionadas com o que é hoje conheci-

El Imperio romano no aportó demasiado

al pensamiento económico. Solo se vio reflejado, en la agricultura con la población campesina y en la ganadería con la clase con más recursos económicos. do como a economia. Os temas abordados pelos pensadores gregos, amplamente relacionados com actividade comercial que teve um desenvolvimento incipiente durante o $B C$ séculos quarto e terceiro Embora pensadores gregos como Heródoto, Teuclides, Hesíodo e Xenofonte foram dedicados ao estudo da economia, contribuindo com algumas teorias, mas a partir de Platão e Aristóteles a ser encontrado conceituações mais sistematizados sobre os aspectos econômicos da vida na "polis ".

Para efeitos do presente estudo fez uso de fontes documentais, é uma proposta histórico exploratório que descreve os primórdios da economia é agora conhecido, através de documentos, livros, coleções têm analisado intelectuais ilustres que conseguiram compilar mais de história.

Ele também tem como objetivo demonstrar a importância histórica das culturas grega e romana para a economia ea importância para a humanidade, embora dependendo do estado da arte, a informação não é muito evidências dessas culturas, ea contribuição para a economia.

Palavras-chave: Doutrinas economias, Economia, Filósofos, Grécia, Roma, de Platão

\section{INTRODUCCIÓN}

Los griegos llamaban "oikos" a la casa incluyendo su interior y a su administrador "nomós", así se formó "okomos" que se describe como "Administración de la Casa". Estos son los inicios de lo que después vendría a denominarse como "economía".

La historia de la economía nace de un análisis económico muy primitivo, más precisamente, de la herencia que se ha recibido de los antepasados, los "antiguos" griegos, sin que del todo hubiera logrado su real identidad.

Los griegos fundieron sus racionamientos económicos en la filosofía general del Estado y de la sociedad, muy pocas veces trataron sustantivamente el tema de manera independiente.

El Imperio romano no aportó demasiado al pensamiento económico. Solo se vio reflejado, en la agricultura con la población campesina y en la ganadería con la clase con más recursos económicos. En cambio, la importancia de esta civilización estuvo evidenciada en el aporte al derecho ${ }^{6} \mathrm{y}$ al manejo de las clases sociales.

Los antiguos griegos, se distinguieron como los grandes contribuyentes de conocimientos en temas como la matemática, astronomía, geometría, la ópti$\mathrm{ca}$, pero en temas económicos, no consiguieron sobresalir, ni siquiera tener una identidad propia. Los griegos desleían sus racionamientos económicos con su filosofía general del Estado y de la sociedad, y pocas veces trataron sustantivamente un texto de economía. Esto explica tal vez el hecho de que su logro en este campo fuera tan modesto, particularmente si se compara con sus resplandecientes hazañas en otros terrenos.

\section{METODOLOGÍA}

Los filólogos clásicos y los economistas que valoran más los aportes griegos están en realidad pensando en aquella filosofía general, y no en la ciencia económica en sentido técnico. Además tienden a caer en el error de olvidar que, en economía como en cualquier otro campo, la mayoría de los enunciados básicos no cobran importancia sino por los fundamentos conceptuales que lo sostienen, y que a falta de ellas, son meras especulaciones.

$6 \quad$ El nacimiento del Derecho romano se debe entre otras causas a la división existente en la sociedad romana entre patricios y plebeyos, no obstante antes del año 451 a. C.-450 a. C., no se conoce un sistema unificado para la península, es por eso que se debe remontar a Grecia cuna de la civilización occidental. 
Los fragmentos científicos del pensamiento económico griego, llegan a la posteridad gracias a las obras de Platón y de Aristóteles (a. C.). Cuando es más abstracto, el pensamiento griego gira siempre en torno de los concretos problemas de la vida humana. Y estos problemas de la vida humana se centraban a su vez alrededor de la idea de la CiudadEstado, "la polis", que ha sido para el griego la única forma posible de existencia civilizada. (Méndez M. El Estado y la organización política).

\section{LOS GRIEGOS}

Los filósofos griegos fueron esencialmente filósofos políticos; desde la polis contemplaron el universo, también el pensamiento y todas las demás cuestiones humanas. Por esto mismo, los temas económicos no fueron parte del interés central, no resultaba una preocupación fundamental en la vida pública. Sin embargo, se encuentra en algunos aspectos claros de la economía.

\subsection{El conocimiento de Sócrates: El maestro}

El método de enseñanza de Sócrates ${ }^{7}$ era el Diálogo, el cual buscaba que el individuo llegara a su interior hasta que efectivamente se conociera a sí mismo, para descubrir la verdad y el bien.

Sócrates incluso fingía ser ignorante en un determinado tema para poder interrogar a su discípulo libremente, sin que aquel se sintiera prevenido. Como dice Platón al citar a su Maestro, usualmente Sócrates decía: "Yo nada sé y soy estéril; pero te estoy sirviendo de instrumento y por eso hago encantamientos, para que puedas dar a luz en tu mente". (Platón, Diálogos).

\subsubsection{El secreto del conocimiento de Sócrates}

Sócrates partía de la base de que sus discípulos eran líderes, eran quienes en un futuro mediato se con-

(470 - 399 a. C.) fue un filósofo griego considerado como uno de los más grandes, tanto de la filosofía occidental como de la universal. Fue el maestro de Platón, quien tuvo a Aristóteles como discípulo; estos tres son los representantes fundamentales de la filosofía griega. vertirían en maestros de otros discípulos que a su vez continuarían con la labor de hacer una mejor sociedad, un mejor Estado, con el simple hecho de conocerse a sí mismos. La participación del alumno en las clases era activa, era de hecho el centro de atención, era el protagonista que encontraba en su interioridad las verdades ocultas sobre cualquier aspecto de la vida y de la política en general. Sin embargo, a Sócrates se le consideró enemigo del pueblo. Sus discursos de que la verdad estaba en el interior de cada uno, eran un escándalo en su época. (Guerra Y., 2009).

Después de Sócrates aparecieron Platón, Aristóteles, y otros tantos pensadores griegos. Cada cual tuvo un método de comprensión de las ciencias diferente entre sí. Aunque en un inicio influidos por Sócrates el Maestro directo de Platón, estos filósofos se apartaron del conocimiento interior del hombre como respuesta a la verdad y se dedicaron a enseñar las ciencias con preguntas y respuestas. El alumno participaba activamente en las conclusiones a las que llegaba con su maestro, aunque en la mayoría de los casos los discursos de los filósofos ya estaban escritos y con el tiempo simplemente se leían a los discípulos.

\subsection{Platón: La economía en la ciudad}

Platón ${ }^{8}$ alumno de Sócrates y maestro de Aristóteles, este aristócrata por esencia describe cómo el origen de la ciudad está forzosamente relacionado a la Economía. En primer lugar, Platón expone que "una persona sola, aislada, no se basta a sí misma para satisfacer sus necesidades básicas. Para Platón las necesidades básicas de la economía son la alimentación, la vivienda, la ropa, el calzado y otras cosas similares. En su opinión quien pudiera satisfacer estas necesidades por sí mismo sería Dios". (La República9: Libro II)

$8 \quad$ Platón, que realmente se llamaba Aristocles y cuyo seudónimo Platón significa el de espalda ancha -debido a que en su juventud había sido atleta-, era hijo de una familia que pertenecía a la aristocracia ateniense, concretamente a la familia denominada Glaucón. Su nacimiento habría ocurrido entre el año 428-427 a.C

9 La República. Es la más conocida e influyente obra de Platón, el compendio de las ideas que conforman su filosofía. Escrita en forma de diálogo entre Sócrates y otros 
El mercado surge porque las personas no pueden abastecerse por sí mismas de todos los elementos que necesitan, ya que nadie La idea de la es capaz de satisfacer esas ciudad que se describe en La República la examina Platón como una ciudad ideal, la cual se reconoce para determinar la forma como la injusticia y la justicia se despliegan en una ciudad según el apetito, espíritu y razón del alma de cada individuo:

- Artesanos o labradores: Los trabajadores correspondían a la parte de "apetito" del alma.

- Guerreros o guardianes: Los guerreros aventureros, fuertes, valientes y que formaban el "espíritu" del alma.

- Gobernantes o filósofos: Aquellos que eran inteligentes, racionales, apropiados para tomar decisiones para la comunidad. Estos formaban la "razón" del alma. (Platón. Diálogos).

Hasta que los filósofos gobiernen como reyes o, aquellos que ahora son llamados reyes y los dirigentes o líderes, puedan filosofar debidamente, es decir, hasta tanto el poder político y el filosófico concuerden, mientras que las diferentes naturalezas busquen solo uno solo de estos poderes exclusivamente, las ciudades no tendrán paz, ni tampoco la raza humana en general.

personajes, como discípulos o parientes del propio Sócrates, se estructura en diez libros, si bien la transición entre ellos no corresponde necesariamente con cambios en los temas de discusión.

10 Tres partes o clases: Trabajadores-Guardianes- Filósofos.
La idea de la ciudad que se describe en La República la examina Platón como una ciudad ideal, la cual se reconoce para determinar la forma como la injusticia y la justicia se despliegan en una ciudad. De acuerdo a Platón, la ciudad "verdadera" y "sana" (La República: libro III).

En todo caso, para Platón el Estado ideal sucederá en una corrupción triste pero necesaria. Así establece este filósofo las categorías de los diferentes estados en un orden de superior a inferior.

- Aristocracia: El gobierno en que el poder está en manos de los nobles y de las clases sociales altas.

- Timocracia: El gobierno en que ejercen el poder los ciudadanos más ricos.

- Oligarquía: El gobierno en el que el poder está en manos de unas pocas personas pertenecientes a una clase social privilegiada ${ }^{11}$.

- Democracia: Sistema político en el que el pueblo elige libremente a quienes lo gobiernan.

- Tiranía: El gobierno en la que el gobernante ejerce un poder total o absoluto, no limitado por unas leyes, especialmente cuando lo obtiene por medios ilícitos ${ }^{12}$.

De acuerdo con otro trazado de Platón, la ciudad surge con la división del trabajo, el cual, a su vez, es el resultado de las diferentes aptitudes naturales de los hombres y de la multiplicidad de las necesidades humanas (ídem: Libro II), es decir, cuando cada persona realiza algo que luego lo intercambia con otros, "trueque", o canje de productos o de productos por bienes, lo que obliga a que cada uno se dedique a aquello a lo que tiene más habilidades de hacer o de realizar.

La especialización en el ser humano, se hace necesaria cuando un producto determinado no puede esperar a quien lo realiza sin dañarse o echarse a perder, por ello, se hace necesaria una organización comercial. (Acuña H., 2011).

\footnotetext{
1 La oligarquía surgió en la antigua Grecia, donde un reducido número de familias controlaba el poder.

12 La Grecia antigua en la que el gobernante alcanzaba el poder por medios ilícitos y lo ejercía sin someterse a leyes.
} 
Por lo anterior da origen al surgimiento de los mercados, también conocido como plaza para la realización de los intercambios requeridos en el proceso de satisfacción de las necesidades de los habitantes de los distintos lugares de la época, es una afirmación hecha por Platón en su obra (La República: Libro IV).

\subsubsection{El precio}

A los mercados se les debe la creación de un nuevo concepto: el de "precio" que era otorgado a los bienes $\mathrm{u}$ objetos mismos del intercambio. Los precios expresaban el valor del objeto transado expresando los insumos y el tiempo de la producción, más una pequeña ganancia para el productor. Los precios eran fijados tasados por un "Agoránomo"13, una persona encargada de realizar el estudio respectivo antes de su asignación. Así las cosas, y en consideración del ilustre griego "el dinero es una creación humana que, debe estar orientada a la solución para el que fue inventada, es decir, al intercambiar elementos para satisfacer necesidades". (La República: Libro IX).

\subsubsection{La usura}

Como una alerta entorno a lo que muy posteriormente se conocería como "usura", Platón presagió que el mercado no tenía la capacidad de autorregularse, lo que hacía imprescindible intervenir la moneda y no permitir la recolección de intereses, como una forma de evitar la obtención de dinero a través del propio dinero. Se puede interpretar el peligro que constituye el acaparamiento de excedentes, que no necesariamente van a la satisfacción de necesidades primarias pero que sí dan lugar a la suntuosidad, al fortalecimiento de mercados externos, de otras ciudades, regiones y países, lo que finalmente sería peligroso en materia de intereses

13 Magistrados encargados de la vigilancia de los mercados. Vigilaban los precios y las transacciones. En ciudades que no poseen astínomos o metrónomos, los agoránomos se ocupaban también de la vigilancia de la calle y de los pesos y medidas, como en el caso de Tasos. En Atenas se designaban por sorteo para un año y eran diez: cinco para la ciudad y cinco para El Pireo. que podrían conllevar inevitablemente a conflictos, incluso a guerras.

Lo deslumbrante de Platón en el terreno de la economía, desde el punto de vista analítico, es la explicación de la división del trabajo, el origen de la Ciudad (Roll. Eric. Doctrinas económicas. pág. 31) de comprender uno de los aspectos claves de esta ciencia: "la existencia de necesidades limitadas" (La República: Libro II), y al recalcar la limitación de las habilidades de las personas para aprovisionarse de bienes, señaló la limitación de recursos, es decir, estos son insuficientes. Lo que ciertamente puede resultar evidente para los contemporáneos, es que este filósofo griego lo planteó con dos mil quinientos años de anterioridad.

\subsection{Aristóteles: Discípulo de Platón}

Dejando de lado a este importante filósofo griego "Platón", para adentrarse en otra insigne figura de la antigüedad griega está Aristóteles ${ }^{14}$, fue el primer economista analítico. No era de origen aristocrático y parece haber aceptado mejor que su maestro el desarrollo de la nueva sociedad.

Él fue quien sentó los cimientos de la ciencia y el primero que planteó los problemas económicos que han estudiado todos los pensadores posteriores (Roll. Eric. pág. 34).

Con planteamientos polarizados frente a los propuestos por Platón, Aristóteles ofrece una visión alterna a la ya expuesta, en este caso, la defensa a la propiedad privada es inminente y debidamente

14 (384 a. C. - 322 a. C.) fue un filósofo, lógico y científico de la Antigua Grecia cuyas ideas han ejercido una enorme influencia sobre la historia intelectual de Occidente por más de dos milenios.

Aristóteles escribió cerca de 200 tratados sobre una enorme variedad de temas, incluyendo lógica, metafísica, filosofía de la ciencia, ética, filosofía, política, estética, retórica, física, astronomía y biología. Es reconocido como el padre fundador de la lógica y de la biología, pues si bien existen reflexiones y escritos previos sobre ambas materias, es en el trabajo de Aristóteles donde se encuentran las primeras investigaciones sistemáticas al respecto. 
argumentada. La defensa a la propiedad privada en Aristóteles bien puede constituir una reacción al pensamiento de Platón, pero ciertamente comunica sus bondades: "la propiedad privada es superior a la propiedad común principalmente porque su productividad es mayor" (La Política: Libro II.), lo que traduce que no es igual el interés que se puede manifestar por los bienes comunes que los propios en tanto los resultados no generan la motivación necesaria para conservar su cuidado y preservación. Ahora bien, volviendo a la insistente relación establecida por los griegos entre la política y la filosofía, esta última enmarcada dentro de un sistema fundamentalmente humanista, añadía Aristóteles a la propiedad privada una serie de favorables impactos sociales, por ejemplo, el hecho de que la generosidad sobre lo propio depende de la autonomía sobre el bien y en este caso no se podría tener el mismo manejo sobre algo que no le pertenece a quien quiera practicar dicha generosidad; igualmente, considerar que la propiedad sobre los bienes sirve como mecanismo de las relaciones entre las personas bajo una condición de uso al que se pueda suscribir.

\subsubsection{El dinero según Aristóteles}

Con relación al dinero, afirmaba Aristóteles: el hombre es el único animal que "tiene palabra y dinero" (La Política: Libro IV.), en su consideración el dinero es algo inventado por el hombre para satisfacer sus propias insuficiencias como sujeto del comercio que es, esto último hace del dinero un bien artificial, no indispensable para el desarrollo de las personas y equivale a obtener una ganancia ilegítima.

Según este filósofo, son tres las características propias del dinero:

- Dinero es una unidad de cuenta cuyo principal servicio es permitir reconocer dentro de un universo determinado cuáles cosas son económicamente más costosas que otras.

- Dinero como medio de cambio, constituye una alternativa a la práctica del "trueque" por considerarse este último de mayor manejo.

- El dinero como una forma de reservar el valor, lo que indica una fortaleza de este medio por cuanto permite la acumulación de la fortuna en el tiempo.
El dinero como símbolo, está destinado a ser usado en el cambio, pero no para acrecentarlo por medio del interés; por naturaleza es estéril y como se multiplica por medio de la usura, ya que esta es la forma más antinatural de multiplicar el dinero.

El discurso aristotélico sobre la "usura" fue ampliado y continuado siglos después por Santo Tomás de Aquino ${ }^{15}$ quien desde su posición eclesiástica manifestó el rechazo al dinero obtenido a través del interés que se debía pagar a los préstamos, así que pronto la posición en contra de la iglesia hizo suya esta visión y fueron los judíos los que optaron por tomar su propio camino en la ruta de la usura, razón por la cual la historia los registra como los actores pioneros en la actividad bancaria.

\subsection{La economía según Aristóteles}

La economía vista por este filósofo, la divide en dos: la economía propiamente dicha, que es la ciencia de la administración doméstica (hogar y la aldea), y la ciencia del abastecimiento, que trata del arte de la adquisición. (Roll. Eric. pág. 35).

De la segunda, Aristóteles analizó el arte del intercambio "trueque", por medio del cual se satisfacen de una mejor manera las necesidades de la primera economía. Pero aquí distingue él, que existe una forma natural y una forma antinatural del cambio,

15 (d. C. 1225-1274) creó uno de los sistemas filosóficos más completos en la historia del pensamiento occidental; al modo de una catedral gótica, con su arquitectura elegante y racional, espigada hacia el cielo, cada concepto está en el lugar que le corresponde, encaja perfectamente con los demás, los soporta, y en su interrelación da lugar a un modelo del mundo pocas veces igualado por otra filosofía. Claro seguidor de Aristóteles, Santo Tomás logra de un modo sorprendente hacerlo compatible con la doctrina cristiana, razón que sin duda explica el éxito que pronto tuvo en toda la cultura cristiana medieval y moderna. No es menor mérito de Santo Tomás el equilibrio que parece lograr entre la razón y su ejercicio y la fe y su práctica; los dos ámbitos le interesaron, aunque, sin duda, el motor de su extraordinario esfuerzo filosófico fue la experiencia religiosa que siempre le acompañó. Por su relevancia e influencias en la historia de la filosofía y, más aún, por mostrarnos una posibilidad del pensamiento (acercarse a lo sagrado y absoluto), Santo Tomás es un filósofo imprescindible para todo aquel que se atreva a pensar con radicalidad la vida humana y el mundo. 
para ello planteo un ejemplo, "un zapato se usa para calzarlo y también para cambiarlo; ambos son usos del zapato" (La Política: Libro I). Con esto se pusieron las bases de diferenciación entre el valor de uso y el valor de cambio que han permanecido hasta hoy.

También, se ilustró con la paradoja del hierro y el oro: "a pesar de que el hierro es mucho más útil que el oro, este tiene un valor mayor" (La Política: Libro I.). La razón fundamental de este hecho es que los bienes más escasos suelen tener un mayor precio, aunque su valor determinado pueda ser menor.

Finalmente, para afianzar lo relacionado a Aristóteles, no se puede desconocer su versión acerca de cómo la riqueza no tiene límites. Esta visión forma parte de la esencia de la economía, en la que se asume que los recursos son escasos y las necesidades son limitadas. Sin embargo, el filósofo diferencia en forma precisa entre riqueza y acumulación de bienes, no es lo mismo tener muchos bienes que disfrutarlos, por lo que Aristóteles utiliza el ejemplo del Rey Midas: "todo lo que tocaba lo convertía en oro. El pobre rey no podía disfrutar de nada, ya que a pesar de tener muchas riquezas, le resultaba imposible gozarlos tal como eran" (La Política: Libro I.), todo esto para demostrar que ser rico no implica la abundancia de bienes sino la fortuna de poder disfrutarlos.

- LOS ROMANOS. Los orígenes de los romanos son un poco oscuros. Son herederos de los etrus $\cos ^{16}$, pero el origen de estos es, aún, más incierto. Su lengua estaba escrita en caracteres grecofenicios, pero aún muchas palabras no están interpretadas La base económica de Roma, en la época de la monarquía $a^{17}$, tuvo su origen en pequeñas comunidades

16 Los etruscos fueron una enigmática civilización que se desarrolló entre los siglos IX y I a. d. C, cuyo núcleo histórico actualmente conocido fue la Toscana a la cual dieron su nombre. Desde la Toscana se extendieron por el sur hacia el Lacio y la parte septentrional de la Campania en donde chocaron con las colonias griegas; hacia el norte de la península itálica ocuparon la zona alrededor del valle del río Po, en la actual región de Lombardía.

17 La monarquía romana fue la primera forma política de gobierno de la ciudad estado de Roma, desde el momento legendario de su fundación el 21 de abril del 753 a. C., agrícolas, con muy escaso comercio y una rígida división en clases sociales. La ganadería era de participación privada, mientras que la agricultura era de manejo de las clases sociales bajas como la campesina y esclava. Aunque, con el tiempo, también sería privada.

El régimen de tenencia era la pequeña propiedad, puesto que cada familia tenía lo que podía explotar directamente.

La base económica de Roma, en la época de la Sin embargo, dada la posición geográfica, la importante abundancia de recursos naturales las ciudades romanas, se dedicaron a comercializar sus productos; principalmente los agrícolas; la ganadería, sal, manufacturas etruscas y demás que pasaban a un segundo plano.

Hasta mediados del siglo IV a. C. Roma no acuñó moneda, y se pagaba con el peso en bronce. (Acuña, 2011).

\subsection{El tetradracma ateniense ${ }^{18}$}

La primera acuñación formal de monedas, según se conoce, la realizaron los lidios ${ }^{19}$ de Asia menor a comienzos del siglo XVII a. C., posteriormente, cada ciudad griega tuvo su propia moneda pero la más importante y valiosa de todas era el tetradracma ateniense, esta moneda llegó a ser determinante en la estructuración de un sistema capitalista que em-

hasta el final de la monarquía en el 509 a. C., cuando el último rey, Tarquinio el Soberbio, fue expulsado, instaurándose la República romana.

18 El tetradracma, también llamada estátera, era una antigua moneda griega equivalente a 4 dracmas, y con un peso de unos 17 gramos. Durante el Imperio romano la tetradracma fue la moneda oficial de Egipto y era equivalente a 1 denario.

19 Herodoto. Los nueve libros de la historia. Libro Primero. Clío. 94. Clásicos Jackson, Vol., XXII. W.M. Jackson Inc. Buenos Aires, 1949. Pág. 40. 
pezó a fortalecerse con el surgimiento de los bancos como lugares específicos a donde se recurría en situaciones de préstamo de dinero o de este mismo como medio para depósito.

\subsection{Los romanos en la economía}

En los tiempos cuando Roma era esencialmente una Comunidad campesina, hubo allí problemas económicos de primerísima importancia que originaron violentas luchas de clases, un antagonismo de intereses entre pobres y ricos. La tradición de la economía romana no presenta un proceso continuo dado sus permanentes guerras y las conquistas que extendían el poderío de Roma, pero fueron acompañadas de graves dislocaciones económicas.

También en ella, aunque de forma desigual a la época contemporánea, hay cambios de desarrollo y cambios de las fuerzas productivas. Estos fenómenos ya se inician en la época primitiva (500 a. C. a 215 d. C.); en la monarquía se puede señalar dos etapas: la latina y la etrusca. La primera, de formación de un estado unitario, y la segunda, de gran fortaleza económica y avanzado desarrollo de las instituciones estatales en las formas clásicas de la "polis". (Acuña H., 2011).

El siglo IV a. C. se caracterizó por los primeros progresos económicos en el campo de la economía por considerarlas logros sociales, que permitieron algunas grandes reformas, políticas y económicas a un tiempo, aunque sin que se modificaran de forma radical los caracteres de las fuerzas productivas. En la época de los orígenes, Roma fue una pequeña aldea de origen indoeuropeo, que estaba descubriendo la agricultura.

También la religión conserva indudables elementos de carácter pastoral de la economía. La propia leyenda sobre los comienzos de Roma, elaborada por historiadores griegos, como Timeo y Jerónimo de Cardia, que tuvieron un conocimiento directo de las noticias, tomándolas primero, según los historiadores posteriores, de las poblaciones agrícolas de la región, parece entrelazarse con elementos de una sociedad pastoril. Analistas, arqueólogos y naturalistas señalan el carácter silvestre y pastoral de
Roma primitiva y una de las puertas de Roma, que daba a camino de los pastos de verano, se llamaba Mugonia. El medio de intercambio y la medida de las multas, a diferencia de otras economías antiguas antes de la moneda, era el ganado.

\subsubsection{Terencio Varrón ${ }^{20}$ : Filósofo y economista romano}

Terencio Varrón (116 a. C.), el más célebre de los economistas romanos, nos expresa que "el nombre del dinero, pecunia, se deriva de pecus, ganado, porque para los pastores, en la antigüedad, el dinero consistía en el ganado" (Morales M. Economía de la Antigua Roma. 2009). Por lo que respecta a la cría del ganado, sin duda los bovinos existían desde época remota; las normas primitivas prohibían matar bueyes, definidos como acompañantes del hombre en el trabajo rustico; al infractor se le sancionaba con la muerte. Pero esta prohibición pertenece a una época en la cual ya se había desarrollado la agricultura. También el caballo era conocido en la edad prehistórica. Su ocupación era más requerida en el ejército que en el trabajo agrícola. Por último, cabras y ovejas pertenecían al más importante pastoreo primitivo de Roma. Diversos historiadores consideran desde la época antigua que existía la necesidad de trasladar los rebaños, según las estaciones, a terrenos adecuados, pero no es cierto que en la Roma antigua hubiera tal posibilidad hacia zonas vecinas, ni puede decirse que las primeras riñas se originaran por disputas alrededor de los pastos.

Sin embargo, una comunidad, por primitiva que sea, no puede vivir solo del pastoreo y por lo tanto muy pronto se desarrollaron formas estables de cultivo del suelo. Un supuesto sobre la que no se tiene ele-

20 Nacido en la ciudad de sabina de Reate, perteneciente a la burguesía conservadora, fue senador, lugarteniente de Pompeyo, gobernador de la Hispania Ulterior. Varón honrado, dotado de una memoria excepcional y poseedor de una cultura enciclopédica, se libró de las proscripciones de Marco Antonio y no cesó de trabajar hasta su muerte, en el 27 a. C., casi a sus 90 años, cuando estaba en pleno fulgor la edad de Augusto. Es el mayor representante de la erudición latina; gracias a su singular mezcla de arcaísmo y actualidad, influyó más que nadie en el remozamiento de la tradición nacional y en la preparación del verdadero clasicismo romano. 
mentos de prueba en la época romana admite que el trabajo de la mujer en la agricultura antigua fue declinado con el empleo del arado, y de ahí nació la preponderancia de los ordenamientos patriarcales sobre los matriarcales.

\subsection{La agricultura romana}

Los cambios surgidos en la base económica y la aparición de la agricultura no carecieron de la influencia sobre la estructura social. La originaria, constituida por grandes grupos originarios dedicados al pastoreo en tierras comunes del grupo, se transformó en una nueva estructura, la de la familia, sobre la base de la propiedad individual de la parcela de tierra para la agricultura, mientras que el pastoreo seguía realizándose en las tierras comunes de los grupos originarios. (Varrón T., Rerum rusticarum libri III).

La creencia más común de la prioridad del pastoreo ha sido rivalizada con la objeción de que sin productos de la tierra no se podía ni siquiera criar ganado. Pero la crítica no es concluyente, pues en la época el ganado se alimentaba de pastos naturales, que no necesitaban cultivo, o de los frutos del bosque, que eran abundantes para las exigencias de la población de la época. (Varrón T., Rerum rusticarum libri III).

Sin embargo, las comunidades que manejaban la agricultura continuaban observando una desigualdad de la riqueza de uno y otros, a causa de los impuestos cada vez mayores, que aumentaban la riqueza de los prestamistas, mercaderes y terratenientes.

\subsubsection{La tierra para cultivo y la familia}

Dos yugadas (media hectárea) constituye un territorio de tierra demasiado reducido para las necesidades, por básicas que fueran, de una familia de cuatro personas, y que hay que creer que la antigua familia romana solía ser más numerosa. En esta época, los nombres adecuados como quinto, sexto, hasta décimo, hacen pensar en familias en las que, a partir de un determinado números de hijos, se solía colocar los nombres según la sucesión de nacimientos.

La idea sobre la posibilidad de que dos yugadas eran suficientes para sostener a una familia solo puede ser poco creíble. No se tienen las condiciones de decir cuál era en aquel tiempo la productividad, teniendo en cuenta que por un lado la tierra era todavía muy fértil, pero por otro lado se cultivaba con métodos básicos rudimentarios.

El propio uso del arado, un tipo de arado primitivo del que se tiene información principalmente por las geórgicas de Virgilio ${ }^{21}$, era poco aconsejable en extensiones no grandes de terreno, porque ni siquiera el producto de siete yugadas es suficiente para alimentar a la vez a los animales y a las familias.

\subsection{Patricios y Plebeyos}

En la antigua Roma la clase social de los patricios estaba compuesta por descendientes de las treinta curias $^{22}$ primitivas. Constituían la clase aristocrática (La nobleza). Eran considerados superiores al resto de los habitantes; gozaban de todos los derechos, poseían tierras y eran los llamados a formar parte del ejército romano. Solo ellos participaban del gobierno. (Roll E., pág. 40).

A medida que Roma crece, la población aumenta a estos nuevos ciudadanos se les denominó la plebe, o plebeyos, en oposición a los descendientes de los antiguos moradores de la ciudad, los patricios.

Con el paso del tiempo, la población plebeya fue mayor a la población noble. Poco a poco los Patricios se fueron viendo obligados a ceder el poder a los plebeyos, cuyo número y poder económico y social crecía incesantemente.

21 Las Geórgicas (publicadas en 29 a. C.) son un poema de Virgilio, el segundo en importancia de entre los que escribió, cuya intención es glosar e informar acerca de las labores agrícolas, además de representar una loa de la vida rural.

22 Una curia, en los tiempos de la Antigua Roma, era una subdivisión del pueblo, más o menos identificada con una tribu. Las tres tribus originales de Roma: Ramnes, Tities, y Luceres, estaban organizadas (10 por cada una) en un total de 30 curias. De esta manera, aportaban al ejército 100 infantes y 10 jinetes por cada curia. A su vez, las curias juntas formaban los Comicios Curiados, asamblea formada por las 30 curias. 
A pesar de haber dedicado buena parte

de sus escritos a

cuestiones claramente

económicas, ninguno

de esos primeros

filósofos-políticos

parece haber buscado

el lazo entre diversos

aspectos de la

realidad económica

que analizaron, ni se

imaginaron hacer de

ellos el objeto de un

conjunto científico
Las presiones ocultas entre los dos grupos fueron creciendo con el paso del tiempo, a medida que las necesidades de patricios $y$ plebeyos se iban equiparando. Así, en algún momento entre el 560 y el 530 a. C. los habitantes plebeyos superaron a la de nobles. Asimismo, los plebeyos pronto conformaron los ejércitos romanos, que hasta entonces había estado reservado solamente a los patricios. Los Plebeyos no pudieron adquirir fuerza económica, porque para la época no había una industria suficientemente desarrollada.

La base de la riqueza de los plebeyos era la explotación colonial, y la usura o monopolios. Por consiguiente, la lucha entre plebeyos y patricios no produjo una nueva clase gobernante, sino la decadencia de la sociedad romana ${ }^{23}$.

Aunque el derecho y las costumbres del imperio no parecen haber influido sobre los males de su orden social. Roma fue el territorio de los mayores movimientos de rebeldía en la antigüedad.

\section{RESULTADOS Y CONCLUSIONES}

La organización económica de las comunidades y la solución de los problemas de sobrevivencia, constituyeron desde las etapas prehistóricas de la evolución humana de las materias primas de la economía, no obstante que esa ciencia había permanecido durante dos mil años solo en estado primitivo.

Los primeros filósofos-políticos universales que se conocen fueron: Sócrates, Platón, Aristóteles en Grecia; Varrón principalmente, en el Imperio Roma- no. Platón se dedicó a la organización de un estado ideal en el cual se evitaban las instituciones decadentes y las injusticias sociales de su época. Aristóteles desarrolló diferentes ideas sobre el Estado y discutió la usura y los salarios, el intercambio y la adquisición, el valor y la acumulación de la riqueza.

A pesar de haber dedicado buena parte de sus escritos a cuestiones claramente económicas, ninguno de esos primeros filósofos-políticos parece haber buscado el lazo entre diversos aspectos de la realidad económica que analizaron, ni se imaginaron hacer de ellos el objeto de un conjunto científico. Sus observaciones en el terreno de la economía formaron más que un conjunto de reglas de moral práctica y de consejos políticos a los soberanos, propiamente un orden científico para la investigación de las cuestiones económicas de la época.

Estos pensadores basaron su doctrina económica en la problemática que se vivía en ese momento, ya que las polis se encontraban desordenadas y solo se limitaban a ser una civilización agrícola, cosa que no simpatizaba a estos pensadores. La sociedad de ese entonces tenía como base o sustento la agricultura y el pastoreo; ya que la mayor parte de su población era campesina.

Los aportes de los filósofos griegos a la economía fue la aproximación racional a la ciencia social en general. Su economía puede describirse como de haber aportado los primeros pasos a los mercados de hoy, no en el sentido de que el comercio estuviese ausente, sino en el sentido de que los productores no eran uniformes ni se comerciaba por medio de intercambios organizado "trueque".

Implementaron la práctica de la administración más que la ciencia de la economía, su economía era básica, pues consistía en la agricultura y en un limitado comercio de intercambio, el Estado para aquella época tenía pocos gastos solo lo concerniente a la manutención y sueldo para el ejército.

La información que se tiene sobre la actividad minorista en Grecia es poca. Los obreros y artesanos solían vender sus propios productos, algunos estaban reunidos en grupos y se dedicaban a la venta del pescado, aceite de oliva y verduras. Las mujeres 
vendían esencias con aromas y elementos decorativos. Los que ofrecían sus productos pagaban un impuesto por el espacio que ocupaban en el mercado y no solían estar bien vistos por la mayoría de la población, siendo objeto a menudo de hacer trampas con las medidas.

La economía estaba poco desarrollada, si se mide por el nivel de pobreza de las masas populares, existía una influencia de la mano de obra agrícola, y el atraso de la tecnología.

Refiriéndonos a los filósofos como Platón, él se interesó por el gobierno y la economía con la división del trabajo y del origen de la ciudad que sirve de preludio a un Estado de República ideal. La debilidad de la economía política de Platón está en que su realización descansa más en el racionalismo que en un proceso social participativo, él solo coincidió con un estado ideal impuesto por la autoridad.

Se puede afirmar que Aristóteles fue el discípulo de Platón, fue el primer "economista" analítico, no era de origen aristocrático y parece haber aceptado mejor que su maestro el desarrollo de la nueva sociedad, en él se evidencia un hondo conocimiento de los principios en que estaba su propia sociedad, él fue quien sentó los principios de la ciencia y el primero que planteó los problemas económicos que han estudiado todos los intelectuales posteriores.

Aristóteles examinó la naturaleza del estado ideal, censuró los proyectos de otros incluso los de su maestro y presentó los suyos. La arremetida de Aristóteles contra la propiedad común se basa en el argumento del estímulo, lo necesario no era prohibir la propiedad privada, sino darle un uso más importante y generoso. Según Aristóteles el estado se dividía "en gobernantes y gobernados", la base seguía siendo la esclavitud y se justificaba alegando que muchas gentes eran esclavas por naturaleza.

La economía de la antigua Grecia era de tipo primitivo pero conforme avanzaba el desarrollo de las ciudades estado esta se fue desarrollando y creciendo.

Los griegos eran principalmente campesinos dedicados a labores de producción agropecuarias, de hecho puede decirse que corresponden a sociedades de autoconsumo; sin embargo, el comercio entre ciudades era también muy importante, claro que estos contactos también se debieron a los continuos enfrentamientos bélicos entre estados. Poco a poco la clase pudiente relegó los deberes a los esclavos mientras ellos se dedicaban a trabajos intelectuales.

\section{Los romanos}

En lo que se relaciona estrictamente con la economía, cabe señalar que los mayores aportes por parte de los romanos han sido:

La plataforma económica de Roma, en la época de la monarquía, era la ganadería de una manera básica; esta era de propiedad privada, mientras que la agricultura era de la clase campesina o general. Aunque, con el tiempo, también sería privada. El régimen de adquisición de tierras eran las pequeñas propiedades, puesto que cada familia tenía lo que podía explotar directamente.

Dada la posición geográfica, los romanos se dedicaron al comercio, principalmente de productos agrícolas; la ganadería, sal, manufacturas etruscas e importaciones griegas y fenicias pasaban a un segundo plano. Aunque la actividad política y cultural se centraba en las ciudades, la mayoría de los habitantes vivían en el campo, donde cultivaban la tierra y cuidaban del ganado. Las siembras más importantes eran las de trigo, vid ${ }^{24}$ y olivo, y también árboles frutales, hortalizas, legumbres y lino. Los romanos mejoraron las técnicas agrícolas. Introdujeron el arado, molinos más eficaces, como el de grano, la prensa de aceite, técnicas de regadío y el uso de abono.

La Cultura romana fue el resultado de un importante intercambio entre civilizaciones diferentes: la cultura griega y las culturas desarrolladas en Oriente (Mesopotamia y Egipto) contribuyeron a formar la cultura y el arte de los romanos. Uno de los vehículos que más contribuyó a la universalización de la cultura romana, que pronto fue la de todo el imperio, fue

24 Sarmentosos y trepadores, de hojas palmeadas, de cuyo fruto en bayas redondeadas y jugosas, agrupadas en racimos, se extrae el vino. 
el uso del latín ${ }^{25}$ como lengua común de todos los pueblos sometidos a Roma.

La familia romana, en oposición de la familia europea actual, estaba constituida no solo por los padres, hijos y parientes, sino también por todos los que vivían bajo la autoridad del cabeza de familia, donde se incluía naturalmente a la servidumbre y los esclavos. La familia romana era legalmente tan fuerte que ciertas cuestiones, que hoy se tratan en los juzgados o en los templos, entonces se trataban en casa, bajo la presidencia del cabeza de familia. La familia era realmente la célula básica de la sociedad romana.

La verdadera innovación de los romanos fue la sistematización y la enseñanza del derecho, que no existía entre los griegos. Por lo tanto, el derecho romano es uno de los grandes aportes de Roma como civilización, supuso la primera recopilación científica de las normas para las que deben regirse las relaciones de los ciudadanos en todos los aspectos fundamentales.

\section{REFERENCIAS BIBLIOGRÁFICAS}

Arguello R. (2000). Manual de Derecho Romano. Historia e instituciones. Editorial Astrea. Buenos Aires, Argentina.

Aristóteles (1988/2005). Obras Completas. Editorial Gredos. Madrid, España.

Aristóteles, (1981/2002). La Política, Editora Nacional, Editorial Espasa Calpe, 2002. Ambas ediciones. Traducción: Carlos García Gual, Madrid, España.

Apele, E. Márquez (1970). Doctrinas Económicas. Segunda edición.

25 El latín es una lengua de la rama itálica de la familia lingüística del indoeuropeo que fue hablada en la Antigua Roma y, posteriormente, por la Edad Media y la Edad Moderna, e incluso la Edad Contemporánea, pues se mantuvo como lengua científica hasta el siglo XIX. Su nombre deriva de una zona geográfica de la península itálica donde se desarrolló Roma, el Lacio (en latín Latium).
Bannock, G., (2003). Diccionario de Economía, Editorial Trillas, Mexico

Círculo de Lectores (1984). Roma. Historia Universal. Tomo III. Bogotá, Colombia.

Codoñer, C. y Fernández C. (1991). Roma y su Imperio; Editorial Anaya.

Ekelund, R., y Hebert R. (1992). Historia de la Teoría Económica y de su Método, $3^{a}$ edición (1992), Editorial Mc Graw-Hill, traducido por: Escutia Jordi, Madrid, España.

Guerra, Y., (2009). Liderazgo, una propuesta pedagógica eficaz. Revista Educación y Desarrollo Social - Bogotá, D. C., Colombia - Volumen 3.

Gutiérrez Rincón (2009). Evolución de la Economía. G. Cotes Publicidad. Barranquilla. Colombia.

Guthrie, W., (1994). Historia de la Filosofía griega. Volumen III: Siglo V. Ilustración. Editorial Gredos. Madrid, España.

Heródoto. (1949). Los nueve libros de la historia. Libro Primero. Clío. 94. Clásicos Jackson, Vol., XXII. W.M. Jackson Inc., Buenos Aires, Argentina.

Historia Universal Planeta (1977). Editorial Planeta, S. A. Tomo I. Barcelona. España.

Hofstätter, H., (1977). Historia Universal Comparada. Tomo I. Editorial Plaza \& Janés S. A. Barcelona. España.

Karataev, N., (1983). Historia de las Doctrinas Económicas. Volumen II, Editorial Grijalbo, Traducido por José Laín.

Martínez V. J., (1994). Pensamiento Económico. Editorial Antillas. Barranquilla. Colombia.

Morales, M., (2009). Economía de la Antigua Roma.

Mochon, F., (2002). Principios de Economía, Editorial Mc Graw Hill, Mexico.

Neurath H. Sieveking (2009). Historia de la Economía. Segunda ed. Traducción. Sánchez S. M. 
Nuevo diccionario etimológico (2006) Latín-Español y de las voces derivadas. Cuarta edición Bilbao: Universidad de Deusto

O. Neurath, H. Sieveking (2009). Historia de la Economía. Segunda edición. Traductor: Manuel Sánchez Santos.

Platón (2003). La República. Editorial Gredos. Madrid, España.

Platón (2009). Introducción General. Diálogos. Volumen I. Editorial Gredos, Madrid, España.

Raymond B., (1973). Economía Política. Tomo I, $7^{a}$ ediciones. Ariel. Barcelona, España.

Roll, E., (1996). Historia de las Doctrinas Económicas, Colombia, $2^{\mathrm{a}}$ edición en español. Fondo de Cultura Económica, traducido por: Torner, Florentino.
Tozzi, G., (2009). Economistas Griegos y Romanos. Traducción: Ángel Tribian.

Villey, D., (1960). Historia de las grandes doctrinas Económicas. Ed. Nova Terra, Traducción. Teresa Vidal.

Scheifler A. X., (1997). Historia del Pensamiento Económico, tomo I, $5^{a}$ edición (1997), Editorial Trillas. México.

Schumpeter J., (1954). Historia del análisis económico. Editorial Ariel, tomo I, Madrid, España.

Weber, M. (1969). Economía y sociedad, Fondo de Cultura económica, México.

Winch, P., (1969). Ciencia social y filosofía, Editorial Amorrortu, Buenos Aires, Argentina. 